\title{
The Occurrence of Heavy Air Pollution during the COVID-19 Outbreak in Beijing, China: Roles of Emission Reduction, Meteorological Conditions, and Regional Transport
}

\author{
Xiao Yan ${ }^{1}$, Aijun Shi ${ }^{2}$, Jingyuan Cao ${ }^{3}$, Tingting Li $^{1}$, Xuesong Sun ${ }^{1}$, Rui Zhang ${ }^{1}$, Xionghui Qiu ${ }^{4,5,6, *}$, Yanxue Li ${ }^{7}$, \\ Miao Liang ${ }^{8}$, Miao Lv ${ }^{9}$, Chunlan Liu ${ }^{1}$ and Jing Wei ${ }^{10}$
}

Citation: Yan, X.; Shi, A.; Cao, J.; Li, T.; Sun, X.; Zhang, R.; Qiu, X.; Li, Y.; Liang, M.; Lv, M.; et al. The Occurrence of Heavy Air Pollution during the COVID-19 Outbreak in Beijing, China: Roles of Emission Reduction, Meteorological Conditions, and Regional Transport. Sustainability 2021, 13, 12312. https:// doi.org/10.3390/su132112312

Academic Editors: Elena Rada and Vincenzo Torretta

Received: 12 October 2021

Accepted: 21 October 2021

Published: 8 November 2021

Publisher's Note: MDPI stays neutral with regard to jurisdictional claims in published maps and institutional affiliations.

Copyright: (c) 2021 by the authors. Licensee MDPI, Basel, Switzerland. This article is an open access article distributed under the terms and conditions of the Creative Commons Attribution (CC BY) license (https:/ / creativecommons.org/licenses/by/ $4.0 /)$.
1 National Engineering Research Center of Urban Environmental Pollution Control, Beijing Municipal Research Institute of Environmental Protection, Beijing 100037, China; yanxiao@cee.cn (X.Y.); litingting@cee.cn (T.L.); sunxuesong@cee.cn (X.S.); zhangrui@cee.cn (R.Z.); liuchunl@cee.cn (C.L.)

2 Beijing Vehicle Emission Management Center, Beijing 100176, China; shiaijun@cee.cn

3 College of Environmental Sciences and Engineering, North China Electric Power University, Beijing 102206, China; jingyuancao@163.com

4 Institute of Transport Energy and Environment, Beijing Jiaotong University, Beijing 100044, China

5 State Environmental Protection Key Laboratory of Sources and Control of Air Pollution Complex, Beijing 100084, China

6 State Key Joint Laboratory of Environmental Simulation and Pollution Control, School of Environment, Tsinghua University, Beijing 100084, China

7 State Grid Integrated Energy Planning, Design and Research Institute, Beijing 100052, China; liyanxue@163.com

8 Meteorological Observation Center, China Meteorological Administration, Beijing 100081, China; liangmiao@163.com

9 CEPEC Talroad Technology CO., Ltd, Beijing 100085, China; lvmiao@163.com

10 Department of Chemical and Biochemical Engineering, Iowa Technology Institute, Center for Global and Regional Environmental Research, University of Iowa, Iowa City, IA 52242, USA; w-jing@163.com

* Correspondence: qiuxh@ncepu.edu.cn

Abstract: To prevent the spread of coronavirus disease (COVID-19) and mitigate the epidemic risk, strict lockdown measures were implemented in Beijing during the quarantine period, significantly reducing human activities. However, severe air pollution episodes occurred frequently in Beijing. To explore the occurrence of severe air pollution during the quarantine period, the impacts of emission reductions, meteorological conditions, and regional transport on heavy air pollution were individually evaluated using the Community Multiscale Air Quality (CMAQ) model. Observations showed that the more unfavorable meteorological conditions which occurred during the pandemic as compared to the corresponding 2019 levels, including higher temperature, relative humidity, and frequency of strong southerly winds, and lower HPBL, led to an increase in $\mathrm{PM}_{2.5}$ concentrations. The model results also showed that the meteorological conditions in February 2020 favored PM 2.5 formation. The $\mathrm{PM}_{2.5}$ concentrations were mainly dominated by regional transport, which became more significant in the quarantine period than in 2019, suggesting the importance of joint control on regional sources for reducing heavy air pollution. This study highlights that, although the emissions in Beijing and surrounding regions were largely reduced during the quarantine period, severe air pollution in Beijing did not reduce due to the unfavorable meteorological conditions.

Keywords: heavy air pollution; COVID-19; meteorological conditions; regional transport

\section{Introduction}

In recent years, air pollution in Beijing has become a matter of public concern, due to high $\mathrm{PM}_{2.5}$ concentration, and frequent and severe heavy haze episodes [1,2]. The Beijing Municipal Government has implemented numerous air pollution control measures since 2013 [1-3], such as the "coal to gas" project, and the replacement of older vehicles. With the 
implementation of these measures, the air quality in Beijing has continuously improved, and the concentration of air pollutants has significantly reduced. For example, ambient $\mathrm{PM}_{2.5}$ concentrations have decreased by $58 \%$ from 2013 to 2020 [4].

However, even though the air pollutant emissions have largely been reduced, heavy air pollution events often occurred during this time period, for example, during the coronavirus disease (COVID-19) epidemic which broke out at the end of 2019 and continues to spread globally $[5,6]$. Beijing took decisive actions to stop the spread of COVID-19, including prohibiting social activities [5,7]. As a result, almost all outdoor human activities stopped, and industrial, transportation, and building activities were substantially reduced. However, the observed concentrations of fine particulate matter $\left(\mathrm{PM}_{2.5}\right)$ in Beijing unexpectedly increased from $53 \mathrm{\mu g} \mathrm{m}^{-3}$ in February 2019 to $63 \mu \mathrm{g} \mathrm{m}^{-3}$ in February 2020. More importantly, severe air pollution episodes occurred during the COVID-19 period in Beijing, with the highest concentration of $\mathrm{PM}_{2.5}$ reaching $206 \mu \mathrm{g} \mathrm{m}^{-3}$. In contrast, the $\mathrm{PM}_{2.5}$ concentrations have reduced in China and Italy, with no significant change in Greece and most cities in the USA [8-10]. This raises interesting questions as to why pollution is increasing in Beijing but not others, and what the major cause of this heavy air pollution in Beijing where the air pollutant emissions experienced a large reduction is. The conclusions from this study are important, as they provide useful information for cities to implement air pollution control strategies when air pollutant emissions are rather low in the future.

Many studies have confirmed that air quality is generally affected by air pollutant emissions and meteorological conditions, such as wind direction (WD), temperature, and relative humidity ( $\mathrm{RH})[7,11-13]$. However, in Beijing, the $\mathrm{PM}_{2.5}$ concentrations were significantly affected by the regional transport of air pollutants from the surrounding Hebei Province and Tianjin $[11,14]$. The official source apportionment of $\mathrm{PM}_{2.5}$ indicated that the regional transport of air pollutants in the surrounding regions contributed $28-36 \%$ to the total $\mathrm{PM}_{2.5}$ concentration in Beijing in 2014, and this value increased to $60 \%$ in the study by Dong et al. [7]. Currently, the individual impacts of emission reductions, meteorological conditions, and regional transport on air quality during the epidemic in Beijing remain unclear.

In the present study, the links between COVID-19 cases with variations in air pollution was investigated. Subsequently, in order to explore the causes of heavy air pollution during the COVID-19 lockdown, the impacts of emission reductions, meteorological conditions, and regional transport on heavy air pollution were separately evaluated. Firstly, the emission reduction during the epidemic was assessed, based on the emission inventory of February 2019 and 2020. Secondly, the impact of meteorological condition on $\mathrm{PM}_{2.5}$ air pollutants was conducted, based on the observations and the sensitivity simulations using the Community Multiscale Air Quality (CMAQ) model. Finally, sensitivity simulations were conducted to assess the impact of regional transport during the COVID-19 epidemic in Beijing.

\section{Methods and Data}

\subsection{Emission Inventory}

The air pollutant emission inventories in Beijing and surrounding regions (Tianjin and Hebei) were established individually for 2019 and 2020. The chemical species included $\mathrm{SO}_{2}, \mathrm{NO}_{x}, \mathrm{VOCs}, \mathrm{PM}_{10}, \mathrm{PM}_{2.5}$, and $\mathrm{NH}_{3}$, and the sectors included power and heating, industrial, residential, fugitive dust, transportation, cooking, waste disposal, fireworks, biogenic, and agriculture. Emissions for each sector were estimated using Equation (1).

$$
E_{i, j}=A_{i} \times \sum_{m}\left(X_{i, m} \times E F_{i, j, m} \times \sum_{n}\left(C_{i, m, n} \times\left(1-\eta_{j, n}\right)\right)\right)
$$

where $i$ represents the emission source, $j$ represents air pollutants, $m$ represents manufacturing technologies, $n$ represents air pollution control technologies, $A$ represents activity levels, $X$ is the fraction of a specific manufacturing technology, $E F$ is the unabated emission 
factor, $C$ is the percentage of a specific pollution control technology, and $\eta$ is the removal efficiency.

The emissions inventory was separately established for 2019 and 2020 in order to evaluate the emission reductions due to the COVID-19 lockdown. The detailed source of sectoral emissions and their activity data were shown in Supplementary Materials (Tables S1 and S2). According to the National Bureau of Statistics of China (NBS) and the Beijing Municipal Bureau Statistics (BMBS), gross domestic product (GDP) decreased by $6.6 \%$ annually, based on comparable prices in Q1-2020. The value added by primary industry was 1.27 billion Yuan, down by $22.9 \%$ year on year. According to the data published by AutoNavi Holdings Limited (available at report.amap.com (accessed on 20 March 2020) and BMBS, the passenger and freight traffic on highways was reduced by $52 \%$ and 32\% in February 2020 as compared to that in 2019, respectively.

\subsection{Air Quality and Meteorological Condition}

In order to study the air quality in Beijing, hourly mass concentrations of air pollutants including $\mathrm{SO}_{2}, \mathrm{NO}_{2}, \mathrm{PM}_{10}$, and $\mathrm{PM}_{2.5}$ in February 2019 and 2020 were obtained from a publicly available website (http:/ / beijingair.sinaapp.com/ (accessed on 20 March 2020). This website contains real-time air quality information, collected from 12 national observation stations at the Beijing Municipal Environmental Monitoring Center (BMEMC, http:/ / www.bjmemc.com.cn/ (accessed on 20 March 2020).

The ground meteorological data, including temperature, $\mathrm{RH}$, and $\mathrm{WD}$, observed at the Beijing Capital International Airport $\left(40.08^{\circ} \mathrm{N}, 116.58^{\circ} \mathrm{E}\right)$, were obtained from the China Meteorological Administration (http:/ / www.cma.gov.cn/ (accessed on 20 March 2020). Historical height of planetary boundary layer (HPBL) data were obtained from the National Centers for Environmental Prediction (NCEP), the Final (FNL) Reanalysis Project implemented by the Earth System Research Laboratory Physical Sciences Division of the National Oceanic and Atmospheric Administration (NOAA), and the University of Colorado Cooperative Institute for Research in Environmental Sciences. The bilinear interpolation method was used to interpolate the HPBL values from the four closest grids. As the horizontal resolution of the HPBL data is $1 \times 1^{\circ}$, the mean HPBL for Beijing was calculated using the data from the four closest grid points.

\subsection{Model Configuration and Experiment Design}

2.3.1. WRF-CMAQ

The WRF-CMAQ (Weather Research and Forecasting and the Community Multiscale Air Quality) model system was used to simulate different air pollutant concentrations, and to evaluate the impact of emission reductions and meteorological conditions on $\mathrm{PM}_{2.5}$ and its major components. The model configurations in this study are the same as in our previous studies $[14,15]$. The two-nested model domain was established with a spatial resolution of $36 \times 36 \mathrm{~km}$ for the first domain (90 rows $\times 90$ columns), and $12 \times 12 \mathrm{~km}$ for the second domain (111 rows $\times 126$ columns), as shown in Figure 1a. A total of 24 vertical layers from the surface pressure to $5000 \mathrm{~Pa}$ were used for this study. The initial and boundary meteorological conditions were derived from the NCEP FNL Operational Global Analysis data (available at http://rda.ucar.edu/datasets/ds083.2 (accessed on 20 March 2020)), with a horizontal resolution of $1 \times 1^{\circ}$ at intervals of $6 \mathrm{~h}$. The main physical schemes of WRF included the Kain-Fritsch cumulus cloud parameterization, the RRTMG radiation mechanism, the asymmetric convective model for the planetary boundary layer, and the Pleim-Xiu land-surface model. The Meteorology Chemistry Interface Processor (MCIP) was used to process the meteorological data in a format required by the CMAQ model. Carbon Bond 6 and AERO7 were selected as the gas-phase and aerosol chemical mechanisms, respectively, in the CMAQ model. 

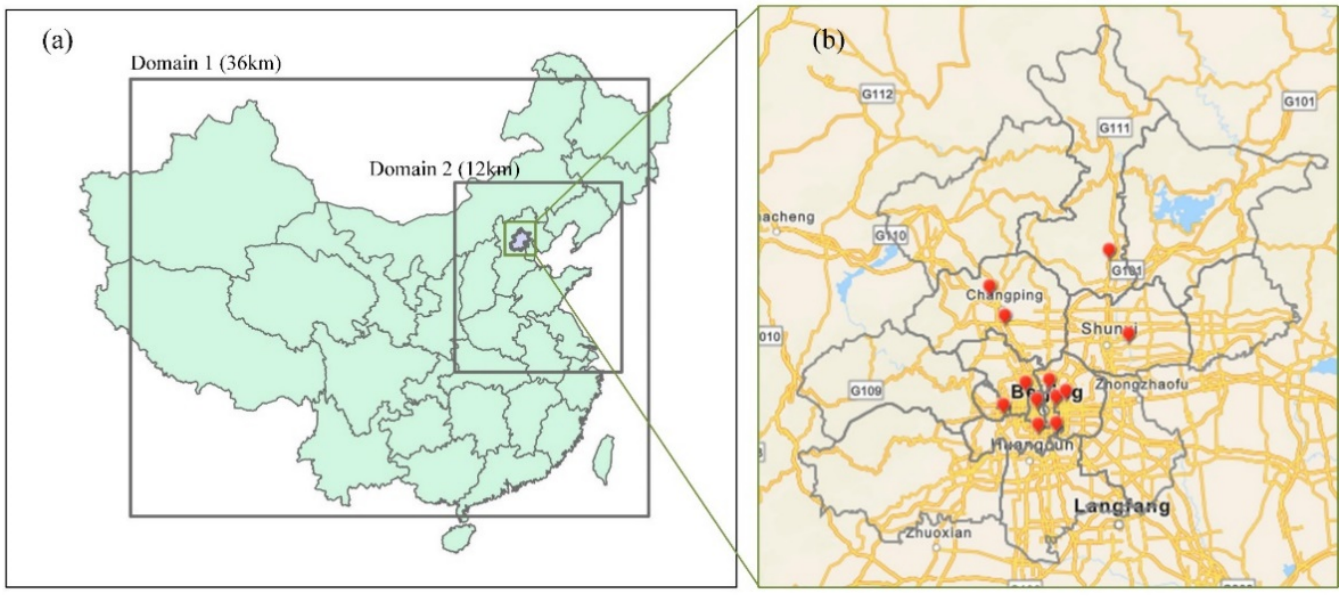

Figure 1. (a) The two-nested CMAQ domain, (b) the observation sites in Beijing.

The integrated source apportionment model (ISAM) module, coupled with the CMAQ model, was applied to distinguish the influences of local sources and regional transport. CMAQ-ISAM is an attached part of the CMAQ model, and uses the trace method to tag the emissions of different regions or sectors, as selected by the user. With the formation of $\mathrm{PM}_{2.5}$, the tag would flow into the final products, and was regarded as the contribution of different sources. The validation results (as shown in Supplementary Materials Table S3) suggest that the $\mathrm{PM}_{2.5}$ concentration is well reproduced and can be used for further analysis.

A scenario analysis was conducted to distinguish the impacts of meteorological conditions, emission reductions, and regional transport. The change in $\mathrm{PM}_{2.5}$ concentrations was attributed to four factors: local contributions due to emission variations ( $\Delta$ Local $\left._{\text {emis }}\right)$, regional transport due to emission variations ( $\Delta$ Regional $_{\mathrm{emis}}$ ), local contribution due to variations in meteorology ( $\Delta$ Local $\left._{\mathrm{met}}\right)$, and regional transport due to variations in meteorology ( $\Delta$ Regional $_{\text {met }}$ ). The E19M19 (both emissions and meteorology based on 2019 data) and E20M20 (both emissions and meteorology based on 2020 data) represent the baseline scenarios of 2019 and 2020, respectively. The differences in the contribution from local sources and regional transport between E20M20 and E19M20 (emissions based on 2019 data, but meteorology based on 2020 data) were considered as the change due to emission reductions, namely $\Delta$ Local $_{\mathrm{emis}}$ and $\Delta$ Regional $_{\mathrm{emis}}$, respectively. Similarly, changes due to meteorological conditions were compared with those of E19M20 and E19M19.

\subsubsection{HYSPLIT}

The air-mass backward trajectories were calculated and clustered to track the transport pathways of the airflow arriving in Beijing $\left(39.914^{\circ} \mathrm{N}, 116.405^{\circ} \mathrm{E}\right)$ using the HYSPLIT model. The 5-day backward trajectories started every hour each day, and were calculated at $50 \mathrm{~m}$ above ground level (AGL) using meteorological data (Global Data Assimilation System, ftp:/ / arlftp.arlhq.noaa.gov / pub / archives/gdas1/ (accessed on 20 March 2020)) during the air pollution episodes. Therefore, a total of 24 trajectories were obtained per day, and trajectory cluster analysis was used to divide the trajectories into distinct clusters, using the TrajStat model.

\subsection{Statistical Analysis}

For exploratory analysis, we fitted generalized linear models to our data using COVID19 cases as the outcomes, and the air pollutant concentrations and emissions as the parameters of interest, adding the corresponding population density values and mean annual earnings as confounding variables. The cumulative number of COVID-19 cases was retrieved from the Beijing Municipal Health Commission (BMHC). The number of deaths in Beijing (9) was too small to be statistically significant. The regional air pollutant concentrations were obtained from the Beijing Municipal Ecology and Environment Bureau. 
Population density (persons $/ \mathrm{km}^{2}$ ) and mean annual earnings were obtained from the BMBS. We modeled the number of cases using Poisson distribution.

Methods for assessing the fit of the model included residual analyses, diagnostic tests, and information criterion statistics. The models were built using the MASS package (www.stats.ox.ac.uk/pub/MASS4/, (accessed on 20 March 2020)) in the R software. The comparison tables were generated using the Stargazer package (Hlavac, 2018). Statistical significance was defined as $p \leq 0.05$.

\section{Results and Discussion}

\subsection{Links between COVID-19 with Air Pollutants}

The associations between the cumulative number of COVID-19 cases and the concentrations of the four major air pollutants recorded in 2019, when no COVID-19 cases were reported, were analyzed. The total levels of $\mathrm{SO}_{2}, \mathrm{NO}_{2}$, and $\mathrm{PM}_{2.5}$ concentration were significant predictors of COVID-19 cases $(p<0.05)$, together with population density and annual earnings. This study provides the first evidence that COVID-19 cases were associated with regional variations in air pollution across Beijing.

We calculated the estimated regression coefficients of each variable and their respective infectivity rate ratios relative to the different air pollutants. Higher $\mathrm{NO}_{2}$ levels corresponded to an increase in COVID-19 cases. The $\mathrm{NO}_{2}$ levels had an infectivity rate ratio of 0.086 , indicating that a $1 \mu \mathrm{g} / \mathrm{m}^{3}$ increase in $\mathrm{NO}_{2}$ concentration in 2019 was associated with $8.86 \%$ more cases in Beijing. Similar to $\mathrm{NO}_{2}$, the levels of $\mathrm{PM}_{2.5}$ showed an infectivity rate ratio of approximately 0.166 . The incidence rate ratios of cases for total emissions and $\mathrm{SO}_{2}$ levels were less than 0 , indicating that higher total emissions and $\mathrm{SO}_{2}$ levels led to lower number of COVID-19 cases. The number of cases was negatively associated with $\mathrm{PM}_{10}$ levels, which was not a significant predictor of the number of COVID-19 cases based on the 2019 air pollution data.

\subsection{Emission Reductions of Air Pollutants during Quarantine Period}

As shown in Figure 2, the emissions of air pollutants in February 2020 were estimated to be $405 \mathrm{t}$ for $\mathrm{SO}_{2}, 3951 \mathrm{t}$ for $\mathrm{NO}_{x}, 5718 \mathrm{t}$ for $\mathrm{PM}_{10}, 1530 \mathrm{t}$ for $\mathrm{PM}_{2.5}, 7805 \mathrm{t}$ for volatile organic compounds (VOCs), and $1789 \mathrm{t}$ for $\mathrm{NH}_{3} . \mathrm{SO}_{2}$ emissions from the residential, and power and heating sectors contributed an average of $60 \%$ and $33 \%$ of the total emissions, respectively. The transportation, power and heating, and residential sectors were the major sources of $\mathrm{NO}_{x}$ emissions, accounting for an average of $49 \%, 36 \%$, and $11 \%$, respectively. The residential, biogenic, and transportation sectors had notable contributions to VOC emissions, accounting for an average of $46 \%, 22 \%$, and $17 \%$, respectively. $\mathrm{NH}_{3}$, which is mainly emitted from the agriculture and waste disposal sectors, accounted for an average of $49 \%$ and $47 \%$, respectively. Fugitive dust was the major emitter of $\mathrm{PM}_{10}$ and $\mathrm{PM}_{2.5}$, with average proportions of $89 \%$ and $73 \%$, respectively.

Air pollutant emissions in Beijing have significantly decreased during the COVID-19 lockdown. The emissions of $\mathrm{SO}_{2}, \mathrm{NO}_{x}, \mathrm{VOCs}, \mathrm{NH}_{3}, \mathrm{PM}_{10}$, and $\mathrm{PM}_{2.5}$ during the quarantine period decreased by $12 \%, 39 \%, 23 \%, 7 \%, 36 \%$, and $35 \%$, as compared to the emissions in 2019 , respectively. Over $94 \%$ of the $\mathrm{PM}_{10}$ and $81 \%$ of the $\mathrm{PM}_{2.5}$ reductions came from reductions in fugitive sources, including construction dust and road dust. According to a published news report (BMCHUD, 2021; DEBB, 2020), the emissions from construction dust decreased by $30 \%$ due to the suspension of construction during the epidemic. The $\mathrm{PM}_{10}$ and $\mathrm{PM}_{2.5}$ emissions from road dust decreased by $52 \%$ in the quarantine period, which was attributed to lower numbers of vehicles on roads. 


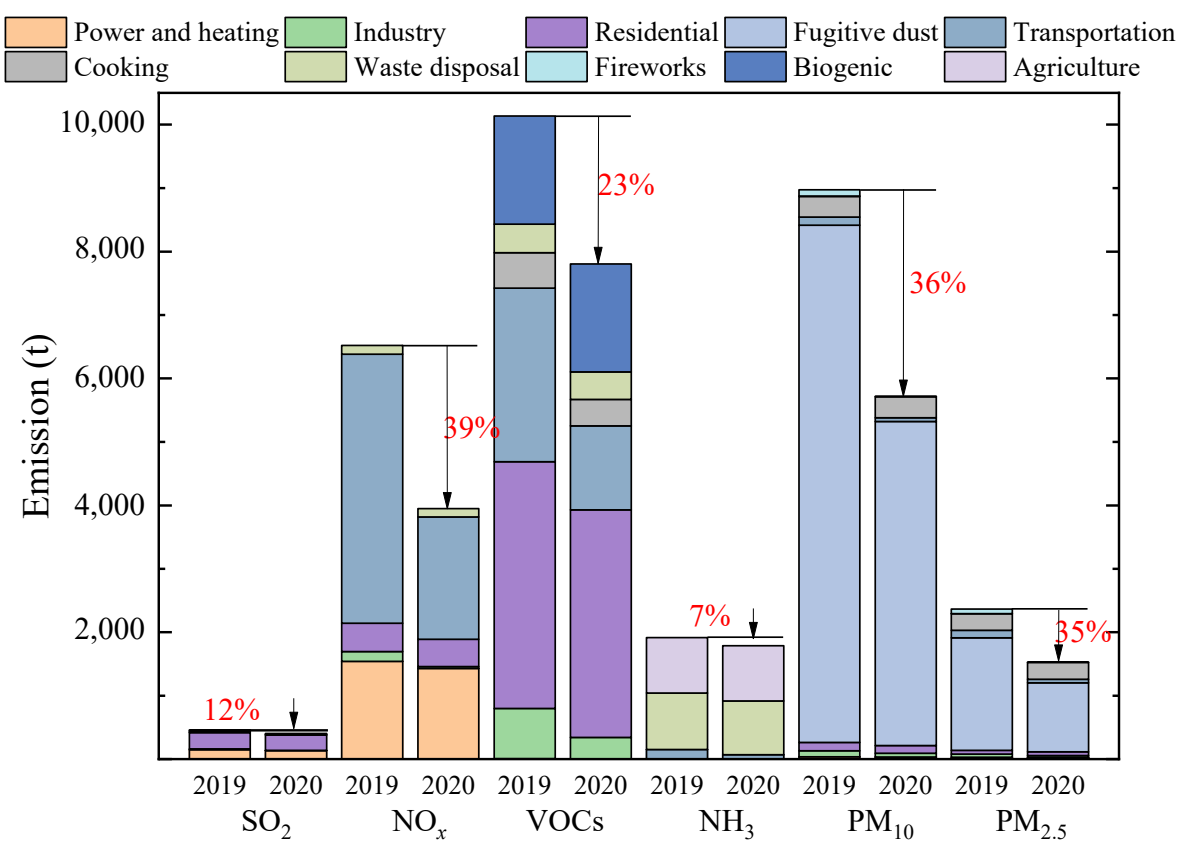

Figure 2. Changes in emissions of $\mathrm{SO}_{2}, \mathrm{NO}_{x}, \mathrm{PM}_{10}, \mathrm{PM}_{2.5}$, VOCs, and $\mathrm{NH}_{3}$ in Beijing during the quarantine period, and the same time period in 2019.

The industrial, residential, and power and heating sectors showed the most notable effects on $\mathrm{SO}_{2}$ emission reductions, accounting for $24 \%, 24 \%$, and $21 \%$ of the emission reductions, respectively. During the epidemic, as people no longer needed to go to work or to school, heating in office and school buildings was entirely shut, which reduced $\mathrm{SO}_{2}$ and $\mathrm{NO}_{x}$ emissions by $5 \%$. The reduction of $\mathrm{NO}_{x}$ emissions from transportation played an important role during the quarantine period, and contributed $95 \%$ to the total reduction. According to the data published by AutoNavi Holdings Limited and BMBS, passenger and freight traffic on highways decreased by $52 \%$ and $32 \%$, respectively, during the epidemic. As a result, the $\mathrm{NO}_{x}$ emissions from vehicles were reduced by $60 \%$ of the transportation reduction. Approximately $24 \%$ of the $\mathrm{NO}_{x}$ emission reductions were attributed to lower air and train traffic during the quarantine period. Transportation, industrial, and residential sectors were the greatest contributors to VOC emission reductions, accounting for $61 \%$, $20 \%$, and $13 \%$ of the total reduction, respectively. The VOC emission reductions in the residential sector were mainly attributed to the fall in demand for paint, due to the decrease in new constructions. The VOC emission reductions in the industrial sector were attributed to the decrease in the use of solvents for paints, coatings, and the chemical industry during the quarantine period. The details on the industrial emission reductions are shown in the Supporting Information. The reduction in transportation activities contributed to $63 \%$ of the total reduction in $\mathrm{NH}_{3}$ emissions (see Supplementary Materials Figure S1).

\subsection{Impact of Meteorological Condition on $\mathrm{PM}_{2.5}$ Air Pollution}

The rate of change in concentrations of $\mathrm{SO}_{2}, \mathrm{NO}_{2}, \mathrm{PM}_{10}$, and $\mathrm{PM}_{2.5}$, and in emissions of $\mathrm{SO}_{2}, \mathrm{NO}_{x}, \mathrm{PM}_{10}, \mathrm{PM}_{2.5}, \mathrm{VOCs}$, and $\mathrm{NH}_{3}$ between the quarantine period and the 2019 levels are shown in Figure 3. The concentrations of $\mathrm{PM}_{2.5}$ increased during the quarantine period, compared to the 2019 levels, although both the primary $\mathrm{PM}_{2.5}$ and its precursor emissions decreased. This is because air pollutant concentrations are affected not only by emissions, but also by meteorological factors, regional transport, and chemical reactions [16]. 


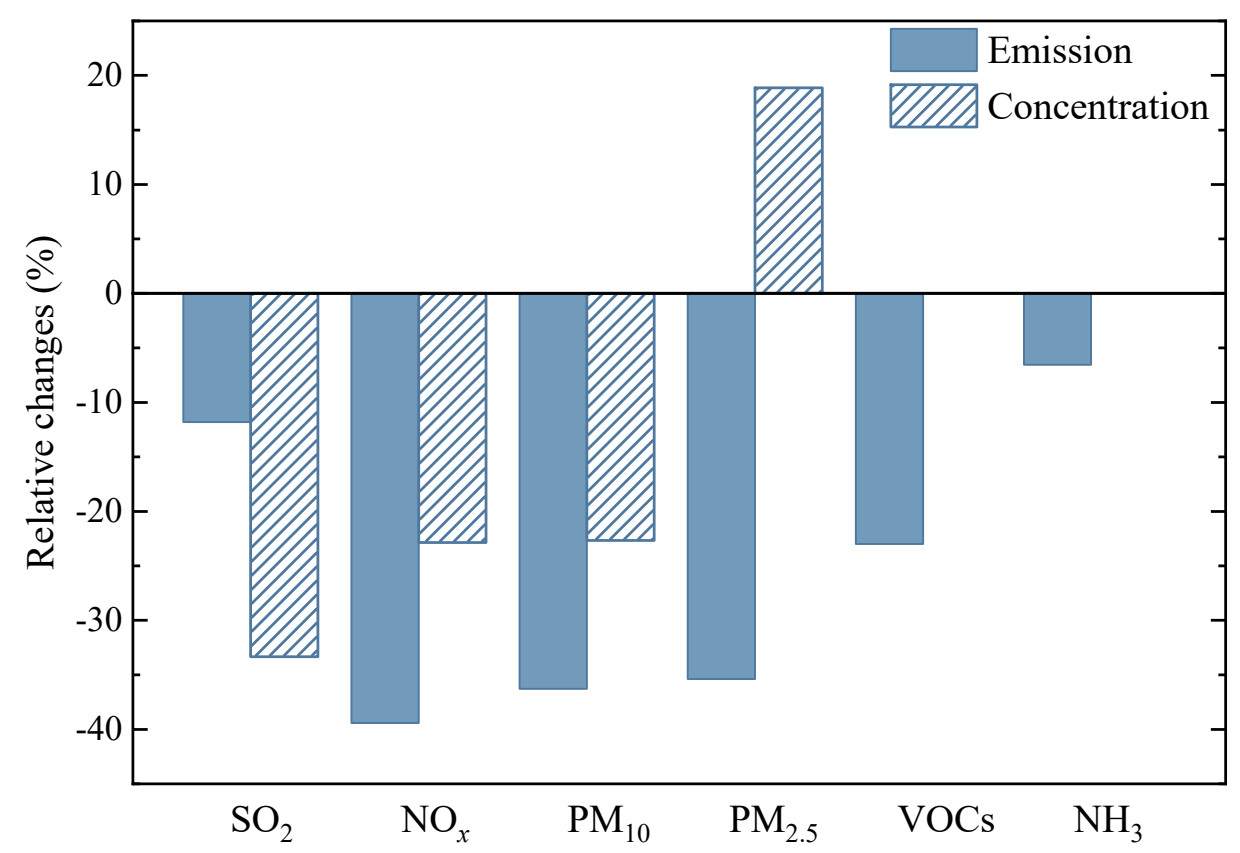

Figure 3. Relative changes in concentrations of pollutants and in emissions of primary pollutants during the quarantine period compared with the 2019 levels.

Assessing the impact of emission reductions on $\mathrm{PM}_{2.5}$ concentrations can be complicated by the variability of meteorological conditions. The daily $\mathrm{PM}_{2.5}$ concentrations, temperature, $\mathrm{RH}$, and WD are shown in Figure 4. It was observed that the $\mathrm{PM}_{2.5}$ concentrations slowly accumulated during the epidemic, followed by a rapid decrease, as determined by the episodic incursion of cold mid-latitude air (cold surges). Following Liu et al. [17], the occurrence of a cold surge was defined as a rapid decrease in surface $\mathrm{RH}$ and temperature, with an increase in surface pressure. One cold surge was identified in February 2020, whereas three were observed in 2019. This led to notable differences in the meteorological variables. Higher RH and temperature in February $2020\left(58 \%\right.$ and $0.5{ }^{\circ} \mathrm{C}$ for 2020 vs. $40 \%$ and $-1.6{ }^{\circ} \mathrm{C}$ for 2019 , respectively) facilitated the formation of secondary aerosols, thereby also contributing to the formation of $\mathrm{PM}_{2.5}[18,19]$. Additionally, strong northerly winds are always associated with the arrival of cold surges [20]. Meteorological conditions in February 2020 were generally more favorable for $\mathrm{PM}_{2.5}$ formation than those in 2019, when there was a high frequency of strong southerly winds (12 days for $2020 \mathrm{vs.}$ 6 days for 2019), which led to the regional transport of pollutants. This can be explained by the HYSPLIT 5-day back trajectory analysis of mass air movements in the haze episode shown in Figure 5. On heavy haze days, more than half of the air trajectories (63\%) arriving at the site came from the south, a region with many high-emission cities. Approximately $36 \%$ of the trajectories were from the northwest. During this period, air movements caused transboundary transportation of pollutants such as $\mathrm{NH}_{3}, \mathrm{SO}_{2}, \mathrm{NO}_{2}$ precursors, and primary PM from southern regions to Beijing, elevating pollutant concentrations. 

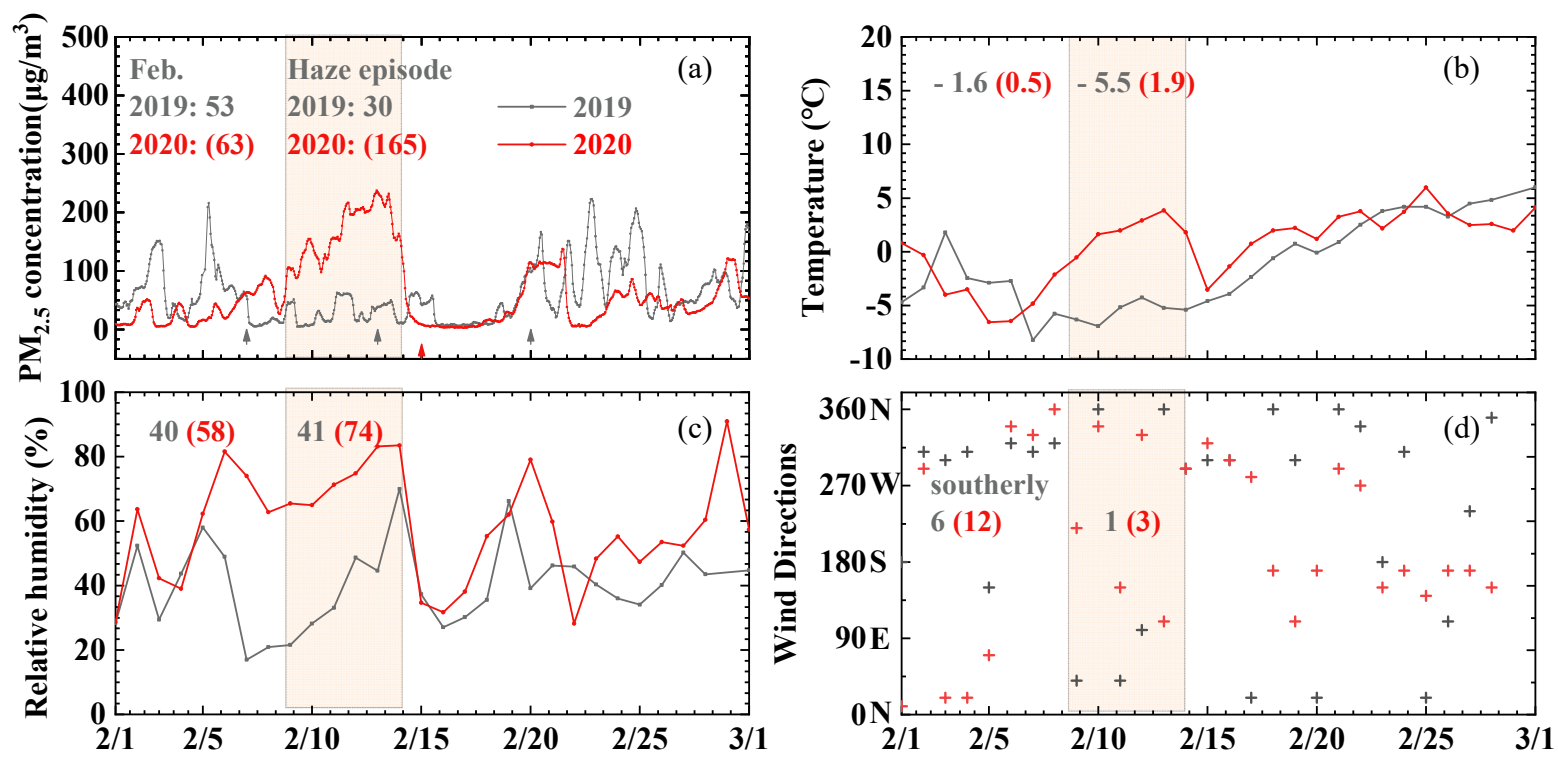

Figure 4. (a) The $\mathrm{PM}_{2.5}$ concentration, (b) temperature, (c) relatively humidity, and (d) wind directions during the quarantine period and 2019 levels. Arrows in the first panel indicate the cold surges identified by an increase in sea-level pressure with rapid decreases in temperature and RH. Mean values for the 2019 and for 2020 (in parentheses) are shown inset.
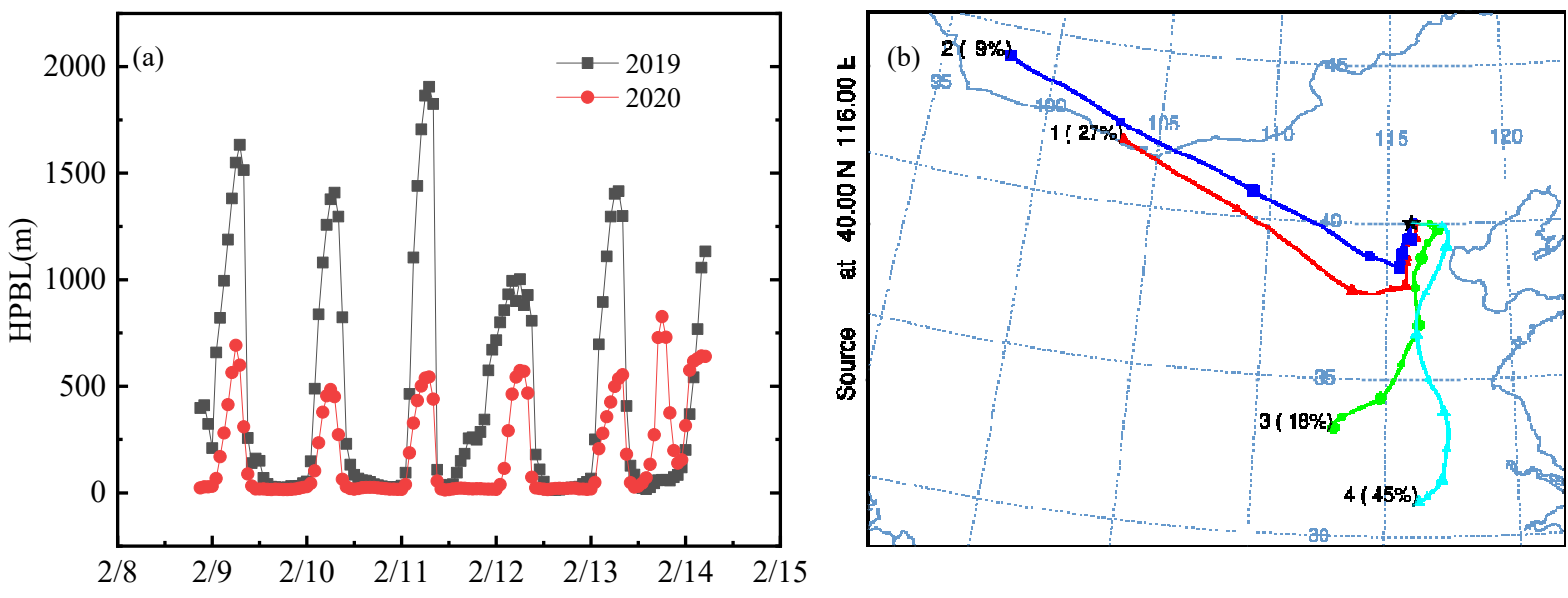

Figure 5. (a) The HPBL and (b) back trajectory analysis during a haze episode.

Finally, $\mathrm{PM}_{2.5}$ concentrations were negatively correlated with HPBL. The HPBL has a diurnal cycle, with high values in the morning and low values in the afternoon. The HPBL of haze episodes that appeared from February 8 to 14, 2020, was lower than the 2019 levels, as shown in Figure 5, which prevented particles from crossing the PBL to the troposphere [13,21,22].

The model performance also indicated that the meteorological conditions in February 2020 benefitted the formation of $\mathrm{PM}_{2.5}$, resulting from a positive change in meteorology by approximately $15.6 \mu \mathrm{g} / \mathrm{m}^{3}$ on average, as shown in Figure 6 . On excluding the meteorological effect, the non-meteorological effects (namely reduced activities) decreased the $\mathrm{PM}_{2.5}$ concentration by $3.4 \mu \mathrm{g} / \mathrm{m}^{3}$. These results indicated that the strict restrictions on human activities significantly decreased $\mathrm{PM}_{2.5}$ concentrations. However, the unfavorable meteorological conditions substantially increased $\mathrm{PM}_{2.5}$, which offset the effect of emission reductions, and caused $\mathrm{PM}_{2.5}$ pollution. The unfavorable meteorological conditions dominated the changes in $\mathrm{PM}_{2.5}$, accounting for $82 \%$ of the model variation, and the emission reductions due to lockdown had limited effects $(18 \%)$. Moreover, the impact of variations in meteorological conditions on SNA (sulfate, nitrate, and ammonium) was higher than that of primary particles, which indicates that the meteorological conditions during the 
epidemic favored the formation of secondary $\mathrm{PM}_{2.5}$. These results are consistent with the data on meteorological variation, and unfavorable meteorological conditions during the epidemic relative to the corresponding 2019 levels were favorable for the formation of secondary $\mathrm{PM}_{2.5}$. The increase in nitrate mass concentrations was more rapid than that of the other components, indicating that nitrate is more sensitive to meteorological variation. As shown in Figure S2 (in Supplementary Materials), nitrate increased by $4.8 \mu \mathrm{g} / \mathrm{m}^{3}$, which is higher than the increases in primary $\mathrm{PM}_{2.5}\left(4.2 \mu \mathrm{g} / \mathrm{m}^{3}\right), \mathrm{SO}_{4}{ }^{2-}\left(3.9 \mu \mathrm{g} / \mathrm{m}^{3}\right)$, and $\mathrm{NH}_{4}{ }^{+}$ $\left(2.6 \mu \mathrm{g} / \mathrm{m}^{3}\right)$.

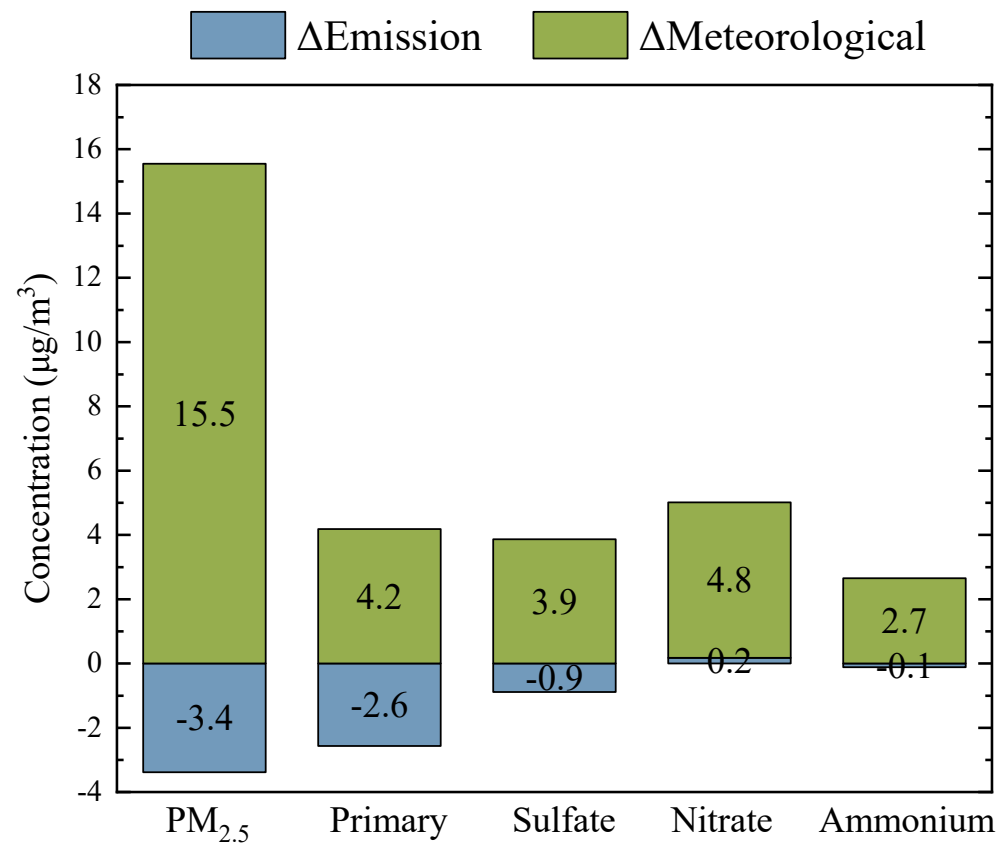

Figure 6. Contributions of different factors to the $\mathrm{PM}_{2.5}$ concentrations and its components during 2019-2020.

\subsection{Impact of Regional Transport on $P M_{2.5}$ Air Pollution}

In order to evaluate the regional contributions of specific emission sources, regional transport for different $\mathrm{PM}_{2.5}$ components, including primary $\mathrm{PM}_{2.5}$ and SNA, were calculated (Figure 6). $\mathrm{PM}_{2.5}$ and its components were mainly dominated by regional transport, with less local emissions. The regional transport of $\mathrm{PM}_{2.5}$ and its components became more significant in the quarantine period than in 2019, suggesting the importance of joint control on regional sources for reducing heavy air pollution. The contribution of local sources during the epidemic increased relative to the 2019 levels, which was attributed to the increase of $70 \%$ and $71 \%$ in sulfate and ammonium concentrations, respectively. This offset the reduction of primary $\mathrm{PM}_{2.5}$ and nitrate concentrations by $13 \%$ and $15 \%$, respectively.

Changes in local sources and regional transport were associated with both emission reductions, and meteorological variations, as shown in Figure 7. The emission reductions not only mitigated the impacts from local sources, but also from regional transport, which reduced $\mathrm{PM}_{2.5}$ by $1.4 \mu \mathrm{g} / \mathrm{m}^{3}$ and $1.9 \mu \mathrm{g} / \mathrm{m}^{3}$, respectively. The $\Delta$ Local $_{\text {emis }}$ of the $\mathrm{PM}_{2.5}$ components was negative, suggesting that the local emission reduction benefit for $\mathrm{PM}_{2.5}$ concentrations had decreased. The $\Delta$ Regional $_{\text {emis }}$ of primary $\mathrm{PM}_{2.5}$ and sulfate was negative, but positive for nitrate and ammonium. The decrease in regional transport in primary $\mathrm{PM}_{2.5}$ and sulfate concentrations was attributed to emission reductions in the surrounding areas. The main reason for the reduced response of nitrate to $\mathrm{NO}_{x}$ emission reductions was the increase in photochemical oxidants, resulting in increased conversion efficiency of $\mathrm{NO}_{x}$ to $\mathrm{HNO}_{3}$. As Beijing is in the VOC-limited ozone formation zone, the higher $\mathrm{NO}_{x}$ emission reductions than VOCs during the epidemic increased $\mathrm{O}_{3}$ and $\mathrm{OH}$ concentrations, and subsequently increased the levels of photochemical oxidants. $\mathrm{NH}_{3}$ is the dominant 
alkaline gas that neutralizes atmospheric $\mathrm{HNO}_{3}$, leading to the formation of $\mathrm{NH}_{4} \mathrm{NO}_{3}$. Thus, the increase in nitrate concentration from regional transport may favor the formation of ammonium, offsetting the decreasing concentration due to $\mathrm{NH}_{3}$ emission reduction.
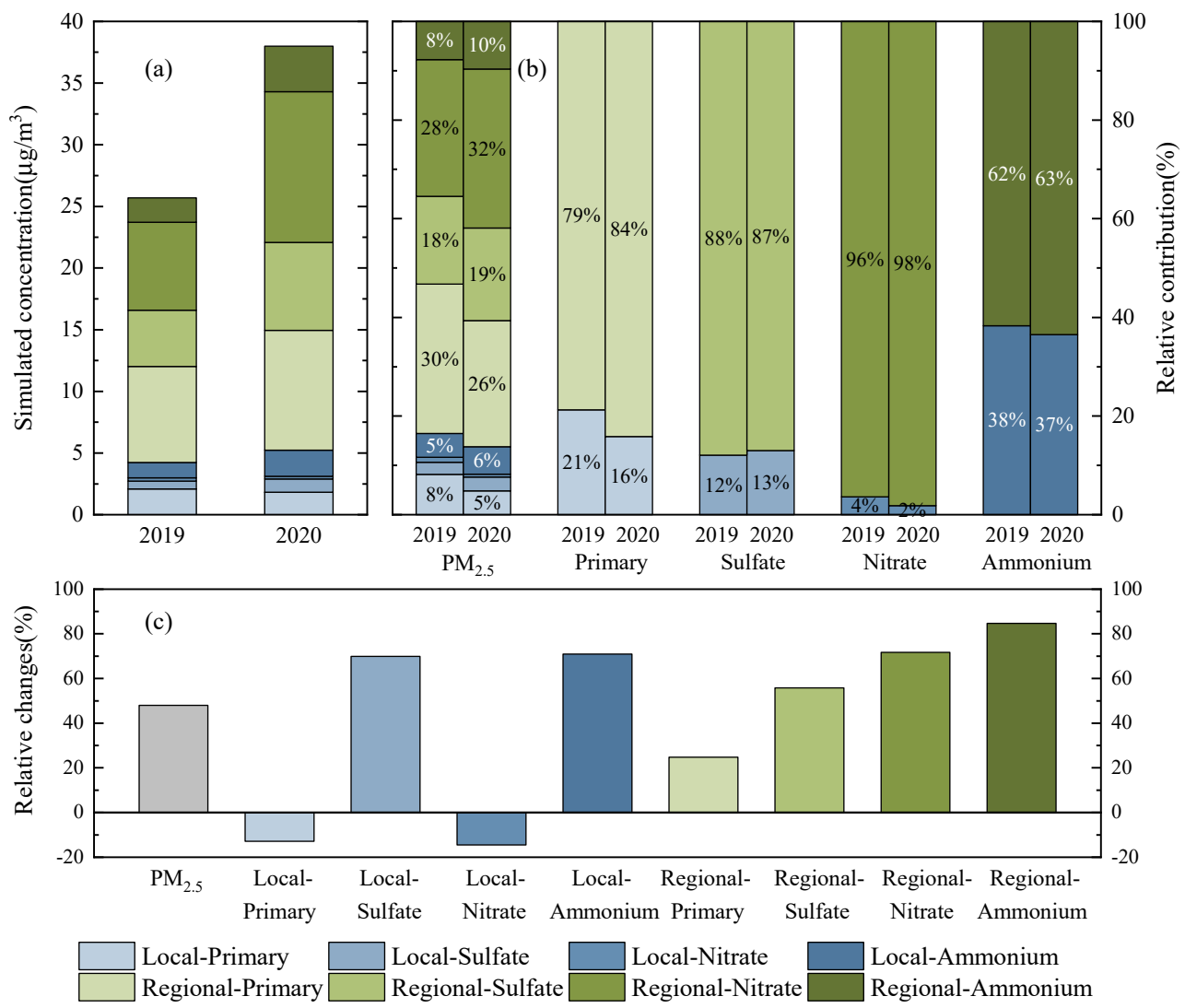

Figure 7. The contribution of local and regional transport to $\mathrm{PM}_{2.5}$ components $(\mathbf{a}, \mathbf{b})$ concentrations, and their relative change (c).

The $\Delta$ Local $_{\text {met }}$ of $\mathrm{PM}_{2.5}$ and its components was positive, implying that meteorological variation might inhibit the transport of pollutants out of Beijing, thus enhancing local concentrations. In addition, the regional meteorological conditions favored secondary particle formation and the transport of pollutants from surrounding areas into Beijing, thus enhancing their concentrations. In addition, compared to local sources, regional transport is more sensitive to meteorological variation, as demonstrated by the $\Delta$ Regional $_{\text {met }}$ being greater than the $\Delta$ Local $_{\text {met }}$ (Figure 6). Furthermore, the contribution of regional transport due to meteorological variation ( $\Delta$ Regional $_{\text {met }}$ ) accounted for $84 \%$ of the increase in $\mathrm{PM}_{2.5}$ concentrations resulting from meteorological variation, with a similar ratio to that of the primary $\mathrm{PM}_{2.5}$ and sulfate. However, the $\Delta$ Regional $_{\text {met }} / \Delta$ Local $_{\text {met }}$ for nitrate was $99 \%$, which was much higher than the total $\mathrm{PM}_{2.5}$, and that for ammonium $(61 \%)$ was much lower than the total $\mathrm{PM}_{2.5}$. This phenomenon was associated with the contribution of regional transport, in which primary $\mathrm{PM}_{2.5}$ and sulfate concentrations were similar to those of total $\mathrm{PM}_{2.5}$. The contribution of regional transport to nitrate was the highest among the $\mathrm{PM}_{2.5}$ components, while that of ammonium was the lowest.

\section{Conclusions}

To prevent the spread of COVID-19 and to mitigate the pandemic risk, strict lockdown measures were implemented in Beijing during the quarantine period, and thus human activities were significantly reduced. However, severe air pollution episodes occurred frequently in Beijing. To explore the occurrence of severe air pollution during the quarantine period, the impacts of emission reductions, meteorological conditions, and regional transport on heavy air pollution were separately evaluated. 
This study provides the first evidence that COVID-19 cases were associated with regional variations in air pollution across Beijing. The results indicated that the emissions of $\mathrm{SO}_{2}, \mathrm{NO}_{x}, \mathrm{VOCs}, \mathrm{NH}_{3}, \mathrm{PM}_{10}$, and $\mathrm{PM}_{2.5}$ during the quarantine period were reduced by $12 \%, 39 \%, 23 \%, 7 \%, 36 \%$, and $35 \%$, respectively, as compared to those during the same period in 2019. The $\mathrm{PM}_{2.5}$ concentrations increased during the quarantine period, as compared to the 2019 levels, although both the primary $\mathrm{PM}_{2.5}$ and precursor emissions decreased, due to unfavorable meteorological conditions and more significant regional transport. Higher temperature, RH, frequency of strong southerly winds, and lower HPBL occurred during the epidemic period, as compared to those in 2019, due to of the less active cold surge, which was conducive to the accumulation of $\mathrm{PM}_{2.5}$. The model results also showed that the meteorological conditions in February 2020 favored $\mathrm{PM}_{2.5}$ formation. The $\mathrm{PM}_{2.5}$ was mainly dominated by regional transport, which was more significant in the quarantine period than in 2019, suggesting the importance of joint control on regional sources for reducing heavy air pollution.

This study highlights that, although the emissions in Beijing and surrounding regions were reduced largely during the quarantine period, they did not help to avoid severe air pollution in Beijing, due to the unfavorable meteorological conditions and increased regional transport. More efforts should be made to avoid severe air pollution in Beijing.

Supplementary Materials: The following are available online at https: / www.mdpi.com/article/10 .3390 / su132112312/s1, Figure S1: changes in emissions of $\mathrm{SO}_{2}, \mathrm{NO}_{x}, \mathrm{PM}_{10}, \mathrm{PM}_{2.5}, \mathrm{VOCs}$ and $\mathrm{NH}_{3}$ in Tianjing and Beijing during quarantine period and the same time in 2019, Figure S2: Contributions of different factors to the $\mathrm{PM}_{2.5}$ concentrations, Table S1: The source of emissions inventory data in Beijing, Table S2: The source of emission inventory data in Tianjin and Hebei, Table S3: Comparisons of simulated 1-h $\mathrm{PM}_{2.5}$ concentrations with observations (Obs: observation, Sim: simulation).

Author Contributions: Conceptualization, X.Y.; methodology, X.Y., X.Q. and J.C.; software, J.W.; investigation, X.Y.; writing—original draft preparation, X.Y.; writing-Review \& Editing, X.Q., X.S. and R.Z. and X.Y.; supervision, X.Q., A.S.; data curation, T.L., J.C.; M.L. (Miao Liang) and M.L. (Miao Lv); Language Editing, Y.L.; Project administration, C.L.; funding acquisition, X.Q., X.Y. and M.L. (Miao Liang). All authors have read and agreed to the published version of the manuscript.

Funding: This research was funded by Beijing Municipal Committee of the Communist Party of China, the National Natural Science Foundation of China (22106043), the National Key Research and Development Program of China (2017YFC0209700), and the State Key Joint Laboratory of Environment Simulation and Pollution Control (20K04ESPCT), Fundamental Research Funds for the Central Universities (2020MS035), State Environmental Protection Key Laboratory of Sources and Control of Air Pollution Complex (SCAPC202004). The contents of this paper are solely the responsibility of the authors, and do not necessarily represent the official views of the sponsors.

Institutional Review Board Statement: Not applicable.

Informed Consent Statement: Not applicable.

Data Availability Statement: Not applicable.

Conflicts of Interest: The authors declare no conflict of interest.

\section{References}

1. Cheng, J.; Su, J.; Cui, T.; Li, X.; Dong, X.; Sun, F.; Yang, Y.; Tong, D.; Zheng, Y.; Li, Y.; et al. Dominant role of emission reduction in $\mathrm{PM}_{2.5}$ air quality improvement in Beijing during 2013-2017: A model-based decomposition analysis. Atmos. Chem. Phys. 2019, 19, 6125-6146. [CrossRef]

2. Xu, Q.; Wang, S.; Jiang, J.; Bhattarai, N.; Li, X.; Chang, X.; Qiu, X.; Zheng, M.; Hua, Y.; Hao, J. Nitrate dominates the chemical composition of $\mathrm{PM}_{2.5}$ during haze event in Beijing, China. Sci. Total Environ. 2019, 689, 1293-1303. [CrossRef] [PubMed]

3. Hua, Y.; Wang, S.; Jiang, J.; Zhou, W.; Xu, Q.; Li, X.; Liu, B.; Zhang, D.; Zheng, M. Characteristics and sources of aerosol pollution at a polluted rural site southwest in Beijing, China. Sci. Total Environ. 2018, 626, 519-527. [CrossRef] [PubMed]

4. Beijing Municipal Ecology and Environment Bureau (BMEEB). Available online: http://www.beijing.gov.cn/ywdt/gzdt/202101 /t20210104_2195891.html (accessed on 20 March 2021). 
5. $\quad$ Le Quéré, C.; Jackson, R.B.; Jones, M.W.; Smith, A.J.P.; Abernethy, S.; Andrew, R.M.; De-Gol, A.J.; Willis, D.R.; Shan, Y.; Canadell, J.G.; et al. Temporary reduction in daily global $\mathrm{CO}_{2}$ emissions during the COVID-19 forced confinement. Nat. Clim. Chang. 2020, 10, 647-653. [CrossRef]

6. WHO. Report of the WHO-China Joint Mission on Coronavirus Disease 2019 (COVID-19); WHO: Geneva, Switzerland, 2020.

7. Dong, Z.; Wang, S.; Xing, J.; Chang, X.; Ding, D.; Zheng, H. Regional transport in Beijing-Tianjin-Hebei region and its changes during 2014-2017: The impacts of meteorology and emission reduction. Sci. Total Environ. 2020, 737, 139792. [CrossRef] [PubMed]

8. Chu, B.; Zhang, S.; Liu, J.; Ma, Q.; He, H. Significant concurrent decrease in $\mathrm{PM}_{2.5}$ and $\mathrm{NO}_{2}$ concentrations in China during COVID-19 epidemic. J. Environ. Sci. 2021, 99, 346-353. [CrossRef] [PubMed]

9. Schiermeier, Q. Why pollution is plummeting in some cities-But not others. Nature 2020, 580, 313. [CrossRef] [PubMed]

10. Varotsos, C.; Christodoulakis, J.; Kouremadas, G.A.; Fotaki, E.-F. The Signature of the Coronavirus Lockdown in Air Pollution in Greece. Water Air Soil Pollut. 2021, 232, 119. [CrossRef] [PubMed]

11. Wang, Y.; Bao, S.; Wang, S.; Hu, Y.; Shi, X.; Wang, J.; Zhao, B.; Jiang, J.; Zheng, M.; Wu, M.; et al. Local and regional contributions to fine particulate matter in Beijing during heavy haze episodes. Sci. Total Environ. 2017, 580, 283-296. [CrossRef] [PubMed]

12. Xing, J.; Wang, S.; Zhao, B.; Wu, W.; Ding, D.; Jang, C.; Zhu, Y.; Chang, X.; Wang, J.; Zhang, F.; et al. Quantifying Nonlinear Multiregional Contributions to Ozone and Fine Particles Using an Updated Response Surface Modeling Technique. Environ. Sci. Technol. 2017, 51, 11788-11798. [CrossRef] [PubMed]

13. Zhang, Q.; Quan, J.; Tie, X.; Li, X.; Liu, Q.; Gao, Y.; Zhao, D. Effects of meteorology and secondary particle formation on visibility during heavy haze events in Beijing, China. Sci. Total Environ. 2015, 502, 578-584. [CrossRef] [PubMed]

14. Xionghui, Q.; Ying, Q.; Wang, S.; Duan, L.; Zhao, J.; Xing, J.; Ding, D.; Sun, Y.; Liu, B.; Shi, A.; et al. Modeling the impact of heterogeneous reactions of chlorine on summertime nitrate formation in Beijing, China. Atmos. Chem. Phys. 2019, 19, 6737-6747. [CrossRef]

15. Qiu, X.; Wang, S.; Ying, Q.; Duan, L.; Xing, J.; Cao, J.; Wu, D.; Li, X.; Chengzhi, X.; Yan, X.; et al. Importance of Wintertime Anthropogenic Glyoxal and Methylglyoxal Emissions in Beijing and Implications for Secondary Organic Aerosol Formation in Megacities. Environ. Sci. Technol. 2020, 54, 11809-11817. [CrossRef] [PubMed]

16. Zheng, B.; Tong, D.; Li, M.; Liu, F.; Hong, C.; Geng, G.; Li, H.; Li, X.; Peng, L.; Qi, J.; et al. Trends in China's anthropogenic emissions since 2010 as the consequence of clean air actions. Atmos. Chem. Phys. 2018, 18, 14095-14111. [CrossRef]

17. Liu, H.; Jacob, D.J.; Isabelle, B.; Yantosca, R.M.; Duncan, B.N.; Sachse, G.W. Transport pathways for Asian pollution outflow over the Pacific: Interannual and seasonal variations. J. Geophys. Res. 2003, 108, 8786. [CrossRef]

18. Rahman, A.; Luo, C.; Khan, M.H.R.; Ke, J.; Thilakanayaka, V.; Kumar, S. Influence of atmospheric $\mathrm{PM}_{2.5}, \mathrm{PM}_{10}, \mathrm{O}_{3}, \mathrm{CO}_{1} \mathrm{NO}_{2}, \mathrm{SO}_{2}$, and meteorological factors on the concentration of airborne pollen in Guangzhou, China. Atmos. Environ. 2019, 212, 290-304. [CrossRef]

19. Wang, P.; Chen, K.; Zhu, S.; Wang, P.; Zhang, H. Severe air pollution events not avoided by reduced anthropogenic activities during COVID-19 outbreak. Resour. Conserv. Recycl. 2020, 158, 104814. [CrossRef] [PubMed]

20. Zhang, Y.; Sperber, K.R.; Boyle, J.S. Climatology and Interannual Variation of the East Asian Winter Monsoon: Results from the 1979-95 NCEP/NCAR Reanalysis. Mon. Weather Rev. 1997, 125, 2605. [CrossRef]

21. Sun, Y.; Zhuang, G.; Tang, A.; Wang, Y.; An, Z. Chemical Characteristics of PM2.5 and PM10 in Haze-Fog Episodes in Beijing. Environ. Sci. Technol. 2006, 40, 3148-3155. [CrossRef] [PubMed]

22. Yao, L.; Lu, N.; Jiang, S. Artificial Neural Network (ANN) for Multi-Source PM P. $_{2}$ Estimation Using Surface, MODIS, and Meteorological Data. In Proceedings of the 2012 International Conference on Biomedical Engineering and Biotechnology, Macao, China, 28-30 May 2012; pp. 1228-1231. [CrossRef] 